\title{
Prevalence of Malnutrition and Associated Factors among Children Age 6-59 Months at Lalibela Town Administration, North WolloZone, Anrs, Northern Ethiopia
}

Birara Melese Yalew*

Federal Ministry of Health Addis Ababa, Ethiopia

\begin{abstract}
Background: Children are most vulnerable to malnutrition in developing countries because of low dietary intakes, lack of appropriate care, and inequitable distribution of food within the household. Malnutrition remains one of the most common causes of morbidity and mortality among children throughout the world. Malnutrition In Ethiopia, in the form of stunting, underweight and wasting were identified as $44 \%, 29 \%$ and $10 \%$ and Amhara National region state $52 \%, 33.4 \%$ and $9.9 \%$, respectively in children under five. The magnitude and various associated factors were not clearly known in the study area.
\end{abstract}

Objective: To determine the prevalence of malnutrition and associated factors among Children age 6-59 Months in Lalibela Town, Northern Ethiopia.

Methods: A-Community based cross-sectional study was conducted from August 19 to September 13, 2012 in Lalibela town, Northern Ethiopia which includes both urban and rural settings. Data were collected from 844 households with children age 6-59 months using pre tested structured questionnaires and measuring weight and height of children. Bivariate and multivariate logistic regression analyses were used using SPSS version 16 computer software to see the relevant associations. Anthropometric data were also converted into indices of nutritional status using Emergency Nutrition Assessment for SMART special software, 2012.

Results: A total of 844 households were included in the study giving the response rate $100 \%$. The prevalence of stunting, underweight and wasting were $47.3 \%(95 \% \mathrm{Cl}: 43.2-51.1), 25.6 \%(95 \% \mathrm{Cl}: 20.6-30.6)$ and $8.9 \%(95 \% \mathrm{Cl}$ : $6.9-10.2)$, respectively. Among the various socio-economic, demographic and child health and care practices characteristics considered, age of the child $11-23$ months (AOR=2.30; $(95 \% \mathrm{Cl}: 1.28-4.12)$, Deworming status (AOR=2.19); $(95 \% \mathrm{Cl}: 1.41-3.39)$, sex of the child (AOR=0.75; $(95 \% \mathrm{Cl}: 0.57-1.00)$ and breast feed the child still now (AOR=0.40; (95\% Cl: $0.20-0.78)$ remained to be significantly associated with stunting. Middle wealth quintile to the households (AOR=0.51; $(95 \% \mathrm{Cl}: 0.28-0.91)$, age of the child $23-35$ months ( $\mathrm{AOR}=2.29 ;(95 \% \mathrm{Cl}: 1.14-4.61)$, number of children aged 6-59 months in the household (AOR=1.61); $(95 \% \mathrm{Cl}: 1.08-2.41)$ and giving honey to the child in the morning $(A O R=1.52 ;(95 \% \mathrm{Cl}: 1.03-2.24)$ were remained to be significantly and independently associated with underweight.

Conclusion: The prevalence rate of malnutrition in the study area was found high and this was coupled with association of many independent variables. This needs appropriate factor specific interventions.

Keywords: Nutritional status; Feeding practice; 6-59 Months children; Lalibela

\section{Introduction}

\section{Statement of the problem}

Nutritional status is the result of complex interactions between food consumption and the overall status of health and health care practices. Numerous socioeconomic and cultural factors influence patterns of child feeding and nutritional status of women and children [1].

Appropriate and adequate feeding is a pre-requisite to good nutritional status in any given time of human life because consumption of nutritionally inadequate diet leads to malnutrition [2]. Proper nutrition in the early years of life is usually determined by feeding practice, which includes the methods and frequency of feeding, degree of stimulation and interaction with parents [3].

Traditional feeding practices are those practices that are directly related to the nutritional and dietary aspects of feeding. Ethiopia is a large country with cultural diversification reflected by different feeding habits and traditional feeding practices [4]. Malnutrition remains one of the most common causes of morbidity and mortality among children throughout the world. It has been responsible, directly or indirectly, for $60 \%$ of the 10.9 million deaths annually among children under five. Over two-thirds of these deaths, which are often associated with inappropriate feeding practices, occur during the first year of life [5].

Malnutrition is one of the leading causes of morbidity and mortality in children under the age of five in developing countries [6]. Ethiopia being one of these countries malnutrition is an important public health problem; stunting, underweight and wasting were identified as $44 \%$, $29 \%$ and $10 \%$ and in Amhara National Region State 52\%, 33\% and $9.9 \%$, respectively in children under five [1].

There is no information available on the stated problem. This study

*Corresponding author: Birara Melese Yalew, Nutritionist/National Nutrition Case Team Coordinator, Federal Ministry of Health Addis Ababa, Ethiopia, Tel: 251 913291992; Fax: 251-115159615; E-mail: biraramelese@yahoo.com

Received October 18, 2013; Accepted December 27, 2013; Published January 22, 2014

Citation: Yalew BM (2014) Prevalence of Malnutrition and Associated Factors among Children Age 6-59 Months at Lalibela Town Administration, North WolloZone, Anrs, Northern Ethiopia. J Nutr Disorders Ther 4: 132. doi:10.4172/2161 0509.1000132

Copyright: (c) 2014 Yalew BM. This is an open-access article distributed under the terms of the Creative Commons Attribution License, which permits unrestricted use, distribution, and reproduction in any medium, provided the original author and source are credited. 
Citation: Yalew BM (2014) Prevalence of Malnutrition and Associated Factors among Children Age 6-59 Months at Lalibela Town Administration, North WolloZone, Anrs, Northern Ethiopia. J Nutr Disorders Ther 4: 132. doi:10.4172/2161-0509.1000132

is, therefore, aimed at assessing nutritional status and associated factors among Children age 6-59 Months.

\section{Literature Review}

\section{Magnitude of the problem}

Under nutrition is one of the most serious but least addressed health problems in the world. The human and economic costs are enormous, falling hardest on the very poor and on women and children. Adequate nutrition is essential for children's health and development [7].

Globally it is estimated that, directly or indirectly, for at least $35 \%$ of deaths in children less than five years of age. Over two-thirds of these deaths, which are often associated with inappropriate feeding practices, occur during the first year of life. Under nutrition is also a major cause of disability preventing children who survive from reaching their full development potential [8].

The Lancet Series on Maternal and Child Nutrition and the 2010 multi-stakeholder global 'Scale Up Nutrition(SUN) effort both emphasize the importance of addressing under nutrition and acute malnutrition in meeting the MDG of reducing child and maternal mortality rates. With four percent of the global death burden in children under five attributable to SAM and $14.5 \%$ attributable to global (moderate and severe) wasting [9]. It is estimated that more than 19 million children around the world are severely acutely malnourished at any one time. These children have a greater than nine fold increased risk of dying compared to a well-nourished child [10].

In developing countries nearly one-third of children are underweight or stunted. Under nutrition interacts with repeated bouts of infectious disease, causing an estimated 3.5 million preventable maternal and child deaths annually and its economic costs in terms of lost national productivity and economic growth are huge [7].

Study done in Vietnam revealed that the prevalence of underweight, stunting and wasting in Nghean was found to be $31.8 \%, 44.3 \%$ and $11.9 \%$, respectively [11]. Other study done in developing countries shows, $32 \%$ or 186 million children below five years of age are stunted and about $10 \%$ or 55 million are wasted [12].

In East Africa $48 \%$ of children under five are affected by stunting [13]. In Ethiopia It is estimated that malnutrition contributes to an estimated 270,000 deaths of under-five children each year [14].

Many nutritional studies have demonstrated that malnutrition in Ethiopia is serious and $44 \%$ of children were stunted, $10 \%$ wasted and $29 \%$ underweight with wide regional variations, in Amhara National Regional State stunting, wasting and underweight were found as $52 \%$, $9.9 \%$ and $33.4 \%$, respectively [14]. Stunting to other regions were $51.4 \%$ in Tigray, $41.4 \%$ in Oromia and 44.1 in SNNPR [1].

\section{Causes of malnutrition}

Malnutrition during childhood is as a result of a wide range of factors, most of which relate to unsatisfactory food intake or severe and repeated infections, or a combinations of the two. The most frequently suggested causes of malnutrition are: poverty, low parental education, lack of sanitation, low food intake, diarrhea and other infections, poor feeding practices, family size, short birth intervals, maternal time availability, child rearing practices and seasonality. There are also economic, social, and cultural causes of malnutrition which underscore the close link between malnutrition [15].

\section{Associated factors}

Socio-economic and demographic factors: Study conducted in Indonesia shows rural children are less likely to be severely, mildly and moderately stunted as compared to urban children. $32 \%$ of rural children are malnourished against $27 \%$ of urban [16]. Study in Vietnam reveals place of residence had significant association with the level of stunting [17]. Ethiopia National baseline survey 2010 also shows a noticeable difference between urban children $(25 \%)$ and rural children $(41 \%)$ in stunting [4]. Children in rural areas are one and a half times more likely to be stunted (46\%) than those in urban areas (32\%) [1]. Female children are more likely to be stunted as compared to male but the association is significant only in case of moderate stunting [16].

Male children were 1.5 times more likely to be stunted as female children [18]. Boys were more likely to be either stunted and/or underweight than girls. Study done in South Africa has shown that male preschoolers were at higher risk of being stunted than their female counterparts [19]. Study done in democratic republic of Congo shows, the prevalence of stunting was higher among boys (46.1\%) compared to girls $(41.7 \%)$, has an inverse linear association with the age of the child (lower in the age groups ranging from 1-4 years [20]. Study in Vietnam indicated that the highest risk of stunting was among children aged 12-23 months and children in the youngest age group, 6-11 months had a significantly lower risk of being stunting than children in the older age groups [21]. Other study in Vietnam also shows that the risk of malnutrition increases with age and a higher prevalence of malnutrition were observed in boys than girls [11]. Study in Nairobi shows, the prevalence of stunting among children aged 6-59 months was $47 \%$, and the prevalence increased with age through 36-47 months (58\%) [22].

Female headed households are more likely to have moderately and mildly stunted children [16]. Families with higher monthly per capita income had significantly lower prevalence of underweight children $(p=0.005)$. Prevalence of stunting was not found to be significantly associated with the number of siblings in India. Those with no siblings, had the lowest proportion of underweight children (12.8\%), higher in those with 1-2 siblings (30.6\%) and highest (51.7\%) in those with $>3$ siblings [23].

Although marginally significant, mothers who had no formal education were four times more likely than mothers who had completed more than primary education to have stunted children $(\mathrm{p}<0.068)$ [1]. Among all the socio-economic factors studied, mother education was found to be the most powerful significant factor associated with malnutrition. Thus, up to $90 \%$ of the children whose mothers were illiterate were found to be malnourished [24].

Study done in Nairobi, designated that mothers' marital status are independently associated to child stunting [24]. Mothers that have at most primary level of education have $43 \%$ of their children stunted compared to $37 \%$ for mothers with at least secondary level of education [24]. Studies shows that the mothers educational level is associated with more efficient management of limited household resources, greater utilization of available health care services, better health promoting behaviors, lower fertility and more child centered caring practices, all of which are associated with better child health and nutrition [25]. The odds of stunting for children born to mothers who were never married are $56 \%$ higher relative to those who are currently in union $(\mathrm{p}<0.05)$. Stunting is more common among children born to single mothers and older mothers, with $45 \%$ and $46 \%$, respectively [24].

The prevalence of underweight and wasting (59.1\% for both) was 
Citation: Yalew BM (2014) Prevalence of Malnutrition and Associated Factors among Children Age 6-59 Months at Lalibela Town Administration, North WolloZone, Anrs, Northern Ethiopia. J Nutr Disorders Ther 4: 132. doi:10.4172/2161-0509.1000132

the highest in children of unskilled laborer and the differences were statistically significant ( $\mathrm{p}=0.004$ and 0.029 , respectively) [26]. A study conducted in Sudan that involves 780 households' shows that the main contributing factors for under-five stunting were found as sex and age of the child [25].

The Ethiopian nutrition baseline survey revealed that, Educational attainment is an important indicator due to its relationship with health behaviors and knowledge; that indicate low educational status affect the feeding practice and nutritional status of children. More children from educated mothers received the colostrums; $76 \%$ of children with a mother who had at least a secondary education compared to $60 \%$ of children whose mothers had no education. Household food source (purchasing or own land production) and type of food consumed have significant impact on feeding practice and expose children to develop malnutrition $[4,25,27]$.

Study conducted in Bangladesh indicated that odds of being severely stunted was significantly $(p<0.05)$ lower for first, third and fourth birth orders than fifth or higher birth orders, while the effect of this variable for being moderately stunted was not significant [28].

A study done to southern region of Ethiopia identified, low socioeconomic status of household, low maternal education, having many children aged under five years and older age of infant as risk factors for child under nutrition [29]. A similar inverse relationship is observed between the household wealth index and the stunting levels of children; that is, a higher proportion of children in the lowest household wealth quintile are stunted (49\%) than of children in the highest wealth quintile $(30 \%)$ [1]. Study conducted by Addis continental institute of public health shows the primary occupation of father was farmers (91\%) [8].

The national nutrition baseline survey also indicated that the main occupation among the rural areas remains farming (86\%) [1]. All the three indices of under-nutrition were higher in incompletely immunized children [30]. The proportion of stunted children was slightly higher for unimmunized children and those without a toilet facility in their household, but the association was not statistically significant [29].

Incidence of diarrhea with two weeks prior to the study showed a significant association with child stunting [29]. All the three indices of under-nutrition were higher in those with worm infestation, the prevalence of underweight children was significant $(p=0.02)$ [30]. Study conducted in Bangladesh shows, after adjustment with other factors, the variables namely household size, number of children in the household and sources of drinking water, appeared to have no significant effect on nutritional status of the children but toilet facilities showed to have a net significant $(\mathrm{p}<0.001)$ effect after controlling for other socio-economic and family related factors [27].

Environmental factors: A study conducted in Ghana shows that the most significant factors that affect nutritional status of under five children were found as, not washing hands after coughing $65 \%$, not washing hands after handling rubbish $11 \%$ and improper washing of raw food 9\% [31]. Study done in Sri Lanka, shows 57\% of the households got drinking water from unprotected well, $10 \%$ from protected/ common well with tube wells, $11 \%$ from boreholes and $10 \%$ from Piped water [32]. Approximately $23 \%$ of households did not use a method of treating drinking water. Among those who used such a method, the most common method used was boiling ( $34 \%$ ), with $24 \%$ of the households using chlorination and another $19 \%$, using filtration. More than $80 \%$ of households wasted less than 15 minutes to access a source of water. In $14 \%$ of all households, there were no toilet facilities [17].

Child health and caring practice: As a global public health recommendation, infants should be exclusively breastfed for the first six months of life to achieve optimal growth, development and health. Non-exclusive breastfed children in the first 4 months had 3.95 times higher incidence of underweight and thereafter, to meet their evolving nutritional requirements. Infants should receive nutritionally adequate and safe complementary foods while breastfeeding continues up to two years or beyond [33].

Appropriate child feeding practices are age-specific, and they are also defined within very narrow age ranges. They follow a continuum from exclusive breastfeeding, starting soon after birth, to the complete adaptation of the child to the family diet [34]. Breastfeeding is an integral part of infant feeding and is the natural form of supplying nourishment to a mammalian infant. The recent study done from 21 countries including Japan, determined that, $87.9 \%$ of 6 to 12 months old infants were breastfed [20].

Children who were breastfed for less than six months were 1.6 times more likely to be stunted than those breastfed long [33]. Apparently, an inverse association is observed between duration of breastfeeding and long-term nutritional status, with longer (more than 6 months) of breastfeeding without starting complementary food associated with increased incidence of stunting [23].

A study conducted in Sudan shows that the main contributing factors for under-five stunting were found as deprivation of colostrums, duration of breastfeeding, pre-lacteal feeds, type of food, age of introduction of complementary feeding and method of feeding [17]. The study conducted among 25 ethnic groups in central, eastern and southern parts of Ethiopia shows that, not practicing exclusive breastfeeding was experienced in the area [35].

A study done on 51 selected wored as from Amhara, Tigray, Oromia and SNNPR shows that the breast feeding practice is estimated to be $98 \%$ but breast feeding was initiated within one hour of birth for $50.4 \%$ of the children who are ever breastfed. $26 \%$ of the children have been given fluids other than breast milk in the first three days after delivery and it is only $59 \%$ of the children who were fed with colostrums [8].

The study on the association between dietary factors and stunting showed that deprivation of colostrum, duration of breastfeeding, prelacteal feeds, age of introduction of complementary feeding, frequency of feeding, mode of feeding and first food given at time of complementary feeding were significantly associated with stunting [18].

Study conduct in SNNPR, shows widely practiced breastfeeding, on-demand feeding, good frequency of breastfeeding, and both breasts feeding contributes towards child growth and healthy development. Exclusive breastfeeding is not yet widely practiced [26]. Age of the child at complementary foods were started had a highly significant negative association with long-term nutritional status. There was a significantly higher percentage of stunting observed among children who started complementary food after 12 months of age as compared to the other groups [18].

A study shows that stunting was higher among children who were bottle fed $50 \%$, hand-fed $39.0 \%$ and received injera $47.6 \%$. The percentage of stunted children complemented with milk and mashed potato was $34.1 \%$ and $34.6 \%$, respectively. A significantly higher 
Citation: Yalew BM (2014) Prevalence of Malnutrition and Associated Factors among Children Age 6-59 Months at Lalibela Town Administration, North WolloZone, Anrs, Northern Ethiopia. J Nutr Disorders Ther 4: 132. doi:10.4172/2161-0509.1000132

proportion of stunted children (49.5\%) were found among those who were fed less than 3 times a day [18].

Behavioral factors: Studies also indicated towards the unhygienic personal habits and adverse cultural practices relating to child rearing, breast-feeding and weaning among tribal communities [36]. Study in SNNPR, shows mothers commonly introduce water, fenugreek, or linseed water, bottle-feeding by considering as good practice, as early as 2 months [29].

The study conducted among 25 ethnic groups in central, eastern and southern parts of Ethiopia shows that faulty traditional beliefs on feeding such as, children couldn't digest meat, choke on thick porridges and food items that are white in color, clean vegetables, colostrums and fruits are prohibited to be consumed by pregnant/lactating women and children [35] (Figure 1).

\section{Justification of the Study}

Despite the fact that the government of Ethiopia health sector has increased its efforts to enhance good nutritional practices, child malnutrition is still among the highest in the world. Children under five are the most vulnerable groups to malnutrition.

Malnutrition is one of the main health problems in Amhara National Regional State as well as to the study area. It is predominantly seen among the rural population since the food source of this population is based on production of crops and the awareness how to prepare and give value to food is limited.

Even though EDHS 2011 reports show malnutrition in Amhara National Regional State is found higher than the national average, the magnitude and various associated factors were not clearly known in the study area. Comprehensive study on the nutritional status and associated factors is needed.

Determining the prevalence and associated factors for malnutrition among children age 6-59 months will assist the health system and other concerned stakeholders to plan appropriate and efficient nutrition

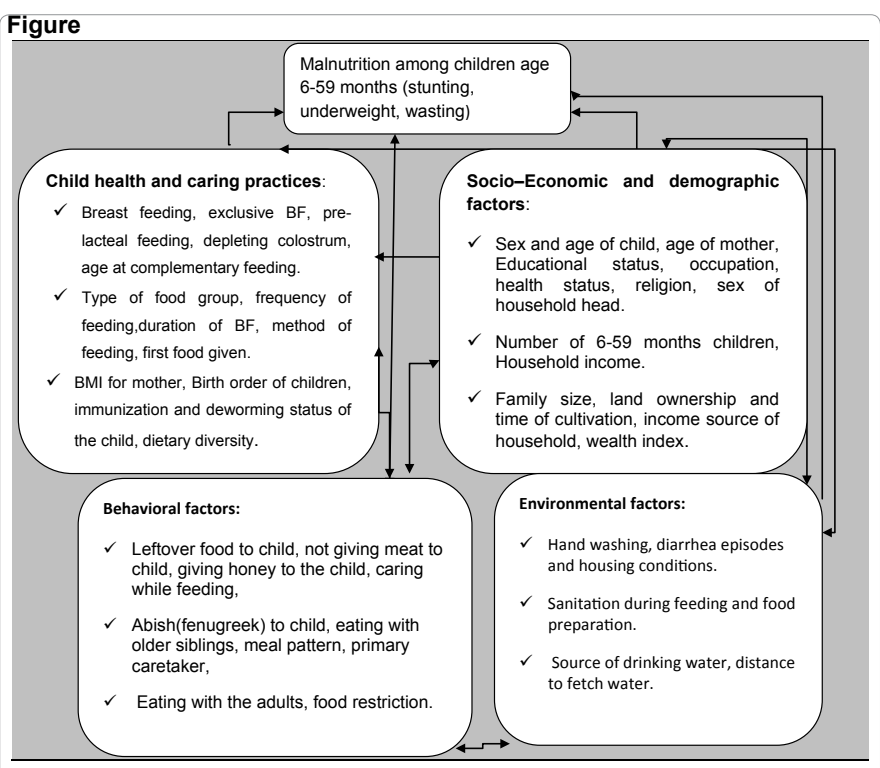

Figure 1: Conceptual Framework for Malnutrition. This is adopted from UNICEF conceptual framework for malnutrition 2012. intervention. There is no recent study done and documented to this specific topic in the area.

\section{Objectives}

\section{General objective}

To assess the prevalence of malnutrition and associated factors among children age 6-59 months at Lalibela Town, North Wollo Zone, ANRS, and Northern Ethiopia.

\section{Specific objectives}

To determine the prevalence of malnutrition among children age 6-59 months at Lalibela town.

To identify associated factors for malnutrition among children age 6-59 months at Lalibela town.

\section{Methods}

\section{Study design and period}

A community based cross-sectional study design was employed from August 19 to September 13, 2012.

\section{Study area}

The study was conducted in Lalibela Town, Northern Ethiopia, which is located about $700 \mathrm{~km}$ away from the capital, Addis Ababa, 300 $\mathrm{kms}$ from the Regional Capital, Bahir Dar and $120 \mathrm{kms}$ from the Zonal Capital Woldia. The town has 5 kebeles, two kebeles in the town (43\%) and three kebeles around the town (57\%). The total population for the year 2004 EFY was estimated at 38,638, children age 6-59 months years old were 4,974 and total households were 7,025 projected from 2007 census of the town [37].

The small town of Lalibela in Ethiopia is home to one of the world's most astounding sacred sites: eleven rock-hewn churches, each carved entirely out of a single block of granite with its roof at ground level. Religious ritual is central to the life of the town, with regular processions, extensive fasts, crowds of singing and dancing priests. This, combined with its extraordinary religious architecture and simplicity of life, gives the city of Lalibela a distinctively timeless, almost biblical atmosphere.

There are one Hospital, one Health Center and three Health Posts in the woreda. The people in this area are engaged in different activities such as farming, irrigation, carpentering, construction and trading.

The socio-cultural interaction is strong which shows working together during harvesting, good participation of celebration (wedding, mahiber, Edir, Ekub) together, etc. In general, the standard of living of these people is low and the environmental sanitation of the town is encouraging. The livelihood of the residents is based on mixed farming. Onion and chili-peppers are the main cash crops, while wheat, teff and legume (bean, peas etc) are the main cereals.

\section{Source of study population}

All children age 6-59 months who were residing at Lalibela town during the study period.

\section{Study population}

Children age 6-59 months who were residing at Lalibela town in selected kebeles during the study period. 
Citation: Yalew BM (2014) Prevalence of Malnutrition and Associated Factors among Children Age 6-59 Months at Lalibela Town Administration, North WolloZone, Anrs, Northern Ethiopia. J Nutr Disorders Ther 4: 132. doi:10.4172/2161-0509.1000132

\section{Study subject}

The study subjects were selected children age 6-59 months in the selected households.

\section{Inclusion and exclusion criteria}

Inclusion criteria: All children age 6-59 months old who were not sick in the selected households.

Exclusion criteria: Children who were seriously ill, because of difficulty of measurement and the significant effect on child malnutrition.

\section{Variables}

Dependant variable: Status of malnutrition in terms of stunting, underweight and wasting.

Independent variables: Socio-economic and demographic factors; Sex and age of child, age of mother, Educational status, occupation, health status, religion, sex of household head, number of 6-59 months children, Household income, family size, land ownership and time of cultivation, income source of household, wealth index.

Behavioral factors: Leftover food to child, not giving meat to child, giving honey to the child, abish (fenugreek) to child, eating with older siblings, meal pattern, primary caretaker, eating with the adults, food restriction.

Child health and caring practices: Breast feeding, exclusive BF, pre-lacteal feeding, depleting colostrum, age at complementary feeding, type of food group, frequency of feeding, duration of BF, method of feeding, first food given, BMI for mother, Birth order of children, immunization and deworming status of the child, dietary diversity.

Environmental factors: Hand washing, diarrhea episodes, housing conditions, sanitation during feeding and food preparation, source of drinking water, distance to fetch water.

\section{Operational definitions}

Anthropometry: Is the measurement of the human body used to assess the nutritional status of individuals and population groups and as eligibility criteria for nutrition support program [38].

Stunting: Moderate and severe; height-for-age Z-score between $-2 \mathrm{SD}$ to $-3 \mathrm{SD}$ and $<-3 \mathrm{SD}$, respectively from the median of WHO reference population [38].

Wasting: Moderate and severe; weight -for- height between -2SD to $-3 \mathrm{SD}$ and $<-3 \mathrm{SD}$, respectively from the median of WHO reference population [38].

Underweight: Weight-for-age Z-score between -2SD to -3 SD and $<-3 \mathrm{SD}$, respectively from the median of WHO reference population [38].

Food group/Dietary diversity): Proportion of children 6-23 months of age who receive foods from 4 or more food groups; The 7 foods groups used includes [39] grains, roots and tubers; legumes and nuts; dairy products (milk, yogurt, cheese); flesh foods (meat, fish, poultry and liver/organ meats); eggs; vitamin-A rich fruits and vegetables and other fruits and vegetables.

Malnutrition: It is the condition that results from an imbalance between dietary intake and requirements. It includes under nutrition, which results from less food intake and hard physical work and over nutrition results from excess food intake and less physical activities [40].

\section{Sample Size determination}

Sample size was computed based on single population proportion formula by using: 95\%CI (two-sided), 5\% margin of error and 52\% proportion of stunting among under five children. The present study had three outcome variables and many associated factors, the prevalence rate of stunting as obtained from the Amhara National Regional State, that gave a relatively larger sample size was taken into consideration [4].

By considering $10 \%$ for non-response rate and 2 for design effect a total sample size of 844 households were proposed.

Formula for single population proportion:

$\left.\mathrm{n}=\mathrm{z}^{2} \mathrm{p}(1-\mathrm{p}) / \mathrm{d}^{2}\right)$

where $\mathrm{Z}=$ level of confidence $(1.96)^{2}$

$\mathrm{P}=$ single population proportion (52\%)

$\mathrm{d}=$ margin of error $(5 \%)$

$\mathrm{n}=$ sample size (384) $\mathrm{HH}$ or children.

Calculation

$\mathrm{n}=(1.96)^{2} \star 0.52(1-0.52) /(0.05)^{2}$

$\mathrm{n}=0.96 / 0.0025=383.55=\sim 384$

$\mathrm{nf}=383.5+(383.5 * 10 \%(\mathrm{Nr}) * 2($ deff $)=843.7=\sim 844$

$\mathrm{nf}=$ final sample size

deff $=$ design effect

$\mathrm{Nr}=$ non-response rate

\section{Sampling and data collection procedures}

Using simple random sampling technique (lottery method) three kebeles, stratified by urban and rural, that comprised about $60 \%$ of the entire population were selected out of five kebeles. From the three selected kebeles 25 clusters were included in the current study by simple random sampling technique.

One cluster contains 34 households. Finally all the study subjects in each cluster were incorporated in to the survey. The number of households taken from each cluster was determined on the basis of proportional allocation to the size of the population to the given kebele. Initially each household were expected to have an average of one child age 6 to 59 months. During the data collection when there were more than one child in the age group 6-59 months one child was selected randomly by lottery method.

In each study area, six enumerators who were able to communicate in Amharic, who had diploma in clinical nursing and preferably had been involved in other similar field surveys, were recruited. Data were collected using pre-tested, adopted structured questionnaire through interviewing mothers or caregivers and measuring weight and height of each child targeted for the survey.

The principal investigator strictly followed the measurement and recording of height and weight of children selected for the study to uphold consistency of anthropometric measurements. Date of birth of children, in most cases was established relying on the date given by the mother or caretaker. For those with written evidence, date of birth was obtained from EPI cards from the households. 
Citation: Yalew BM (2014) Prevalence of Malnutrition and Associated Factors among Children Age 6-59 Months at Lalibela Town Administration, North WolloZone, Anrs, Northern Ethiopia. J Nutr Disorders Ther 4: 132. doi:10.4172/2161-0509.1000132

Anthropometric measurements were also taken for all children aged 6-59 months to assess their nutritional status; Length of the child aged 6-23 months was measured in a recumbent position to the nearest $0.1 \mathrm{~cm}$ using a board with an upright wooden base and a movable headpiece. Height of children (24-59 months of age) was measured in a standing-up position to the nearest $0.1 \mathrm{~cm}$ using vertical board with a detachable sliding headpiece which was designed by UNICEF.

Weight of the child was measured with light clothing and without shoes to the nearest $0.1 \mathrm{~kg}$ using UNICEF Electronic Scale (Item No.HD-318 TANITA digital bathroom scale). Children that can't stand in the weigh scale were measured together with his/her mother or caregiver, the mother was weighed with the child and weighed without the child and then subtract weight of the mother from the total weight. The difference between the two measures is the child's weight.

In addition to the child anthropometric measurement the survey also address weight and height of the mother or care giver to calculate BMI. The nutritional status of children was assessed using the indicators weight-for-age, weight-for-height, and height-for-age, according to WHO reference standard by taking $-2 \mathrm{SD}$ as the cut-off point indicating malnutrition in terms of stunting, underweight and wasting.

Measurement was taken according to anthropometric measuring guide procedure. Accuracy of all anthropometric measurements was upheld according to the international reference standard. Multistage sampling technique and proportional allocation methods were employed to obtain sample size from each stratum and cluster.

The formula used to calculate sample size of stratum was:

$\mathrm{ni}=\left(\mathrm{n}^{\star} \mathrm{Ni}\right) / \mathrm{N}$ where $\mathrm{ni}=$ sample size for each stratum $\mathrm{n}=$ total sample size

$\mathrm{Ni}=$ total population to each stratum $\mathrm{N}=$ total population for the whole study area (Figure 2).

\section{Data quality management}

Data collecting tools were pre-tested by involving 40 children from similar area, which was not included in the study. Some modifications were made on the basis of the finding and Data validity and reliability were maintained through close supervision of enumerators by the principal investigator and the two supervisors.

Five percent of sample sizes were re-interviewed by the supervisors to ensure the accuracy of data collected by the team.

The collected data were checked out for the completeness, accuracy and clarity. Weight scales were carefully handled and periodically calibrated by placing standard calibration weights of $2 \mathrm{~kg}$ iron bars on the scale to ascertain accuracy.

For effective and quality data collection, a two day intensive training was given to the selected enumerators and supervisors. The training was given on the topics; study objectives, a thorough review of the questionnaire, the use of survey instruments, interview techniques, and direction as to how to interview the mother or care giver using the structured questionnaire, how to take anthropometric measurements and ethics during field work in line with predesigned training module.

The data collection tool was first adopted in English and then translated in to Amharic then back to English to maintain the consistency of each question. The data collectors were four male and two female health professionals with diploma in clinical nursing and two Health officers as supervisor.
The data entered was checked for its consistency. Frequencies and cross tabulations were used to check for missed values and variables. Finally, Errors identified were corrected after revising the original questionnaire.

\section{Data processing and analysis}

The analyses were started by data entering, coding and cleaning. Data entry into the computer was carried out using the EPI INFO version 6, window 2002 statistical packages. After completion of data entry, recorded data of the EPI INFO was exported to SPSS version 16 and then description of frequencies, means, proportions, SDs and rates of a given data for each variable were accomplished.

Logistic regression analysis was carried out at two levels. Firstly, a bivariate analysis was performed to determine the differentials of children age 6-59 months stunting, underweight and wasting by explanatory variables. Secondly, those predictor variables which were significantly associated with the outcome variable at 0.2 and less level of significance from the bivariate analyses were entered into the multivariate logistic regression model.

P-value $<0.05$ was considered as statistical significant and Odds ratio with 95\%CI to see important association. The model fitting for multivariate analysis was checked with Hosmer and Lemeshow goodness of fit.

Backward stepwise LR was used for selection of significant predictors in the multivariate logistic regression analysis. Adjustment of variables using logistic regression was made for predicting variables that were associated with stunting, underweight and wasting of children

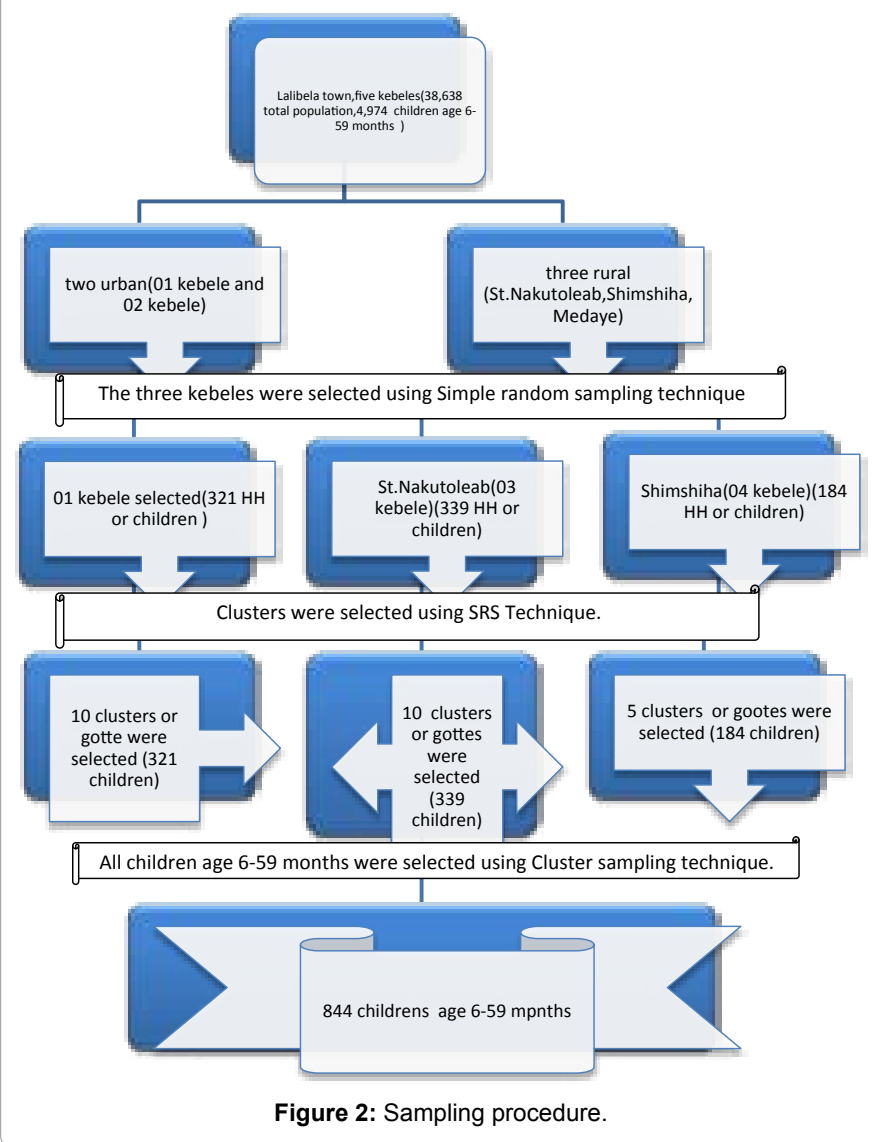


Citation: Yalew BM (2014) Prevalence of Malnutrition and Associated Factors among Children Age 6-59 Months at Lalibela Town Administration, North WolloZone, Anrs, Northern Ethiopia. J Nutr Disorders Ther 4: 132. doi:10.4172/2161-0509.1000132

age 6-59 months during crude analysis. The dichotomous variable stunting, underweight and wasting were defined as $1=$ for stunted: $0=$ for not stunted. $1=$ for underweight and $0=$ for not underweight and $1=$ for wasted and $0=$ for not wasted. Coefficients were expressed as crude and adjusted OR relative to the reference category.

Anthropometric data were also converted into indices of nutritional status using Emergency Nutrition Assessment (ENA) for SMART special software, 2012.

\section{Ethical Considerations}

Ethical clearance was obtained from Institutional Review Board of Institute of Public Health, College of Medicine and Health Sciences, University of Gondar and official consent were also granted from Amhara Regional Health Bureau/ Regional Health Research Laboratory Center/, North Wollo Zonal Health Department and Lalibela Town Administration Health Office for official start of the study.

Letters were also prepared to the local authority of the selected kebeles, health centers head and health posts by the woreda health office. The purposes and importance of the study were explained at all levels and oral informed consents were secured from each household. All households were assured that the data will not have any negative repercussion on any aspects of their life. Confidentiality was maintained by not exposing or sharing the information gathered from the respondents at all levels of the study.

Households selected for the study were on their verbal consents; households who were not voluntary to interview were informed to do so without any restriction. Eight children who were found severely malnourished during the anthropometric measurement were referred to the nearby health facilities for treatment.

\section{Dissemination and Utilization of Results}

The results of the study will be shared to the community, the study kebeles, Lalibela Town Administration Health Office, North Wollo Zonal Heath Department, Amhara National Regional Health Bureau/Regional Health Research Laboratory Center/ and respective administrative offices for appropriate intervention.

The finding will also be presented to Institute of Public Health, College of Medicine and Health Science, University of Gondar as part of applied human nutrition post graduate thesis and I will also present/share to other organizations that are in need of the result. Finally publication will be considered through peer review journals and presentation in meeting/conferences to find financial and technical support for the implementation.

Based on the finding, resource mobilization will be done and following getting the budget required, proper planning and implementation strategy will be developed in collaboration with the woreda Health office and then start supporting the local community by providing appropriate nutrition education and other important nutrition intervention.

\section{Results}

\section{Socio-economic and demographic characteristics of households}

A total of 844 households were included in the study giving the response rate $100 \%$. Out of these households $811(96 \%)$ were mothers and the remaining $33(4 \%)$ were caregivers and fathers. The mean age of the respondents was 30.8 years with a SD of 7.48 years.
Of total households involved 505 (60\%) were rural and 339 (40\%) were urban.

About 435 (52\%) of the study children were male. The mean age of children was 33.5 months with SD of 14.98 months. Households with one child age 6-59 months were $681(81 \%)$ and more than one child were 163 (19\%). The majority of mothers were married 646 (77\%), Orthodox Christian religion followers 819 (97\%).

About 525 (62\%) of mothers were illiterate and the rest 319 (38\%) were literate. Only 77 (9.1\%) of the mothers were able to read and write while the corresponding figure for fathers 197 (23.3\%) were more than double of the females. The prevalence of Stunting, underweight and wasting were high in those children whose mothers were can't read and write $(213(25.5 \%), 127(15 \%)$ and $47(5.6 \%))$ compared to children whose mothers were educated up to higher level (14 (1.7\%), $3(0.4 \%)$ and $2(0.2 \%))$, respectively.

Father's occupation in the present study indicated as 401 (47.5\%) were farmers, and 255 (30\%) were farmer-priest. From health related indicators, deworming service was $726(86 \%)$ and children vaccinated were about $830(98 \%)$ (Table 1).

\begin{tabular}{|c|c|c|c|}
\hline Characteristic & $\begin{array}{c}\text { Urban }(n=339) \\
\text { No }(\%)\end{array}$ & $\begin{array}{c}\text { Rural }(n=505) \\
\text { No }(\%)\end{array}$ & $\begin{array}{c}\text { Total }(n=844) \\
\text { No }(\%)\end{array}$ \\
\hline \multicolumn{4}{|c|}{ Age of the child in months } \\
\hline $6-11$ & $31(4)$ & $45(5)$ & $76(9)$ \\
\hline $12-23$ & $68(8)$ & $94(11)$ & 162(19) \\
\hline $24-35$ & $85(10)$ & $111(13)$ & 196(23) \\
\hline $36-47$ & $88(10)$ & $150(18)$ & $238(28)$ \\
\hline $48-59$ & $67(8)$ & $105(13)$ & $172(21)$ \\
\hline \multicolumn{4}{|l|}{ Sex of the child } \\
\hline Male & 193(23) & $242(29)$ & $435(52)$ \\
\hline Female & $146(17)$ & $263(31)$ & $409(48)$ \\
\hline \multicolumn{4}{|c|}{ Literacy rate of mother } \\
\hline Illiterate & $169(20)$ & $356(42)$ & $525(62)$ \\
\hline Literate & $170(20)$ & 149(18) & $319(38)$ \\
\hline \multicolumn{4}{|c|}{ Number of children per HHs } \\
\hline One child & $295(35)$ & $386(46)$ & $681(81)$ \\
\hline More than one child & $44(5)$ & $119(14)$ & 163(19) \\
\hline \multicolumn{4}{|l|}{ Family size } \\
\hline $2-4$ & $240(28)$ & $265(32)$ & $505(60)$ \\
\hline $5-7$ & $91(11)$ & $228(27)$ & $319(38)$ \\
\hline $8-11$ & $8(1)$ & $12(1)$ & $20(2)$ \\
\hline \multicolumn{4}{|l|}{ Occupation of the father } \\
\hline Farmer & $39(5)$ & $362(43)$ & $401(48)$ \\
\hline Merchants & $135(16)$ & $53(6)$ & $188(22)$ \\
\hline Farmer-Priest & 165(19) & $90(11)$ & $255(30)$ \\
\hline \multicolumn{4}{|c|}{ Household income per month } \\
\hline$<500$ ETB & $87(10)$ & $183(22)$ & $270(32)$ \\
\hline $500-1000$ ETB & $172(20)$ & $244(29)$ & $416(49)$ \\
\hline$>1000$ ETB & $80(10)$ & $78(9)$ & 158(19) \\
\hline \multicolumn{4}{|l|}{ Wealth quintile } \\
\hline Lowest & $4(1)$ & $255(30)$ & $259(31)$ \\
\hline Second & 14(1) & $48(6)$ & $62(7)$ \\
\hline Middle & $29(3)$ & $106(13)$ & $135(16)$ \\
\hline Fourth & $128(16)$ & $71(8)$ & 199(24) \\
\hline Highest & 164(19) & $25(3)$ & $189(22)$ \\
\hline
\end{tabular}

Table 1: Socio-demographic characteristics of children and their parents by resident, Lalibela Town, North Wollo Zone, ANRS, Northern Ethiopia, August 2012. 
Citation: Yalew BM (2014) Prevalence of Malnutrition and Associated Factors among Children Age 6-59 Months at Lalibela Town Administration, North WolloZone, Anrs, Northern Ethiopia. J Nutr Disorders Ther 4: 132. doi:10.4172/2161-0509.1000132

\section{Environmental health and housing characteristics of the study subjects}

From the total 844 households, 594 (70\%) had Corrugated iron roof houses. From these households 317 (38\%) were urban and 277 (33\%) to rural. Households with thatched as roofing materials were about 250 (30\%), out of these $228(27 \%)$ were rural and only $22(3 \%)$ were urban.

From the total household participated in the study 483 (57\%) were reported owning some land used for agriculture, 361 (43\%) did not. Of rural households 385 (46\%) owned land and only 98 (11\%) of urban households own land. About 717 (85\%) of the households in the study area had latrine, this proportion was different in urban and rural areas with $280(33 \%)$ and $437(52 \%)$, respectively.

About 667 (78.6\%) of the households used piped water as source of drinking water. Among rural areas, 87 (10\%) were using river as source of drinking water, $48(6 \%)$ were using unprotected well and springs.

Overall, households treat water for drinking purposes were about 263 (31\%). About 753 (89\%) of households reported that they washed their hands after toilet. From this 317 (38\%) were urban and 436 (52\%) were rural households. Among rural households, 69 (8\%) reported that they did not wash their hands after toilet use.

\begin{tabular}{|c|c|c|c|}
\hline Characteristic & $\begin{array}{c}\text { Urban }(n=339) \\
\text { No }(\%)\end{array}$ & $\begin{array}{c}\text { Rural }(n=505) \\
\text { No }(\%)\end{array}$ & $\begin{array}{c}\text { Total }(n=844) \\
\text { No }(\%)\end{array}$ \\
\hline \multicolumn{4}{|l|}{ Latrine } \\
\hline Yes & $280(33)$ & $437(52)$ & $717(85)$ \\
\hline No & $59(7)$ & $68(8)$ & $127(15)$ \\
\hline \multicolumn{4}{|l|}{ Household land owned } \\
\hline Yes & $98(11)$ & $385(46)$ & $483(57)$ \\
\hline No & 241(29) & 120(14) & $361(43)$ \\
\hline \multicolumn{4}{|c|}{ Number of harvesting time $(n=484)$} \\
\hline Once a year & $98(12)$ & $364(43)$ & $462(55)$ \\
\hline Twice a year & $1(0.1)$ & 21(2) & $22(2.1)$ \\
\hline \multicolumn{4}{|c|}{ Roof material for the main house } \\
\hline Corrugated iron & $317(37)$ & $277(33)$ & $594(70)$ \\
\hline Thatched & $22(3)$ & $228(27)$ & $250(30)$ \\
\hline \multicolumn{4}{|c|}{ Floor material for the main house } \\
\hline Erthen & $323(38)$ & $503(59.8)$ & $826(97.8)$ \\
\hline Cement & 16(2) & $2(0.2)$ & $18(2.2)$ \\
\hline \multicolumn{4}{|l|}{ Source of drinking water } \\
\hline River & $9(1)$ & $87(10)$ & $96(11)$ \\
\hline Piped water & $328(38.8)$ & $334(40)$ & $663(78.8)$ \\
\hline Protected well and spring & $1(0.1)$ & $36(4)$ & $37(4.1)$ \\
\hline $\begin{array}{l}\text { Unprotected well and } \\
\text { spring }\end{array}$ & $1(0.1)$ & $48(6)$ & $48(6.1)$ \\
\hline \multicolumn{4}{|c|}{ Distance to fetch drinking water } \\
\hline Less than an hour & $247(29)$ & $464(55)$ & 711(84) \\
\hline One hour or more & 18(2) & 28(3) & $46(5)$ \\
\hline Water on premises & 74(9) & $13(2)$ & $87(11)$ \\
\hline \multicolumn{4}{|l|}{ Hand washing with soap } \\
\hline yes & $317(37)$ & 393(47) & 710(84) \\
\hline No & $22(3)$ & 112(13) & $134(16)$ \\
\hline \multicolumn{4}{|l|}{ Presence of diarrhea } \\
\hline yes & $59(7)$ & 74(9) & 133(16) \\
\hline No & $280(33)$ & $431(51)$ & $711(84)$ \\
\hline
\end{tabular}

Table 2: Environmental characterstics of households by place of resident, Lalibela Town, North Wollo Zone, ANRS, Northern Ethiopia, August 2012.
When we see washing hands before feeding the child, almost all of households washed their hands 840 (100\%), with little difference between urban 338 (40\%) and rural 502 (59.5\%) (Tables 2 and 3).

\section{Child feeding practices among the study subjects}

The most prevalent traditional feeding practices that children had undergone were giving leftover food to child 296 (36\%), bottle feeding practiced 237 (28\%), giving pre-lacteal feeding 158 (19\%) and depleting colostrum 155 (18\%). Those children who were not exclusively breast feed before 6 months of age were about 30 (3\%). Lately initiation of breastfeeding 45 (5\%), which was usually noted to be the worst type of malpractice, was not a common phenomenon among the population of the town.

From the present study male children were slightly affected to the most common type of traditional feeding practices of the area than female children. Not giving the first milk (colostrum) and giving prelacteal fed to a newborn baby as the first feed were higher among female children than male (Table 3).

\section{Nutritional status of children age 6-59 months}

The analysis of the three anthropometric indices height-for-age, weight-for -age and weight-for-height revealed that $47.3 \%, 25.6 \%$ and $8.9 \%$ of the total 844 children included in the survey were found to be stunted, underweight and wasted, respectively.

Stunting/height-for- age/: Among children aged 6 to 59 months, 399 (47.3\%) (95\%CI; 43.2-51.1) were stunted. This rate is lower for younger children and increases around 12 to 23 months of age. There was little difference between boys 215 (25.5\%) and girls 184 (21.8\%). There was a noticeable difference between urban children 147 (17.4\%) and rural children 252 (29.9\%). There were also differences in the levels of stunted children among mothers of different educational levels. Children with highly educated mothers were less likely to be stunted $14(1.7 \%)$ than children of those with mothers who had a primary education $104(12.3 \%)$ and those mothers with no education 215 (25.5\%). Severe stunting (below - 3 SD) was 137 (16.2\%) (95\%CI; 14.1-18.4) among all children and this shows slightly higher in males 77 (9.1\%) than females $60(7.1 \%)$.

Wasting/weight-for-height/: Among children age 6 to 59 months, $75(8.9 \%)$ were wasted. Unlike stunting, younger children were more likely to be wasted than older children. This might be due to the increased susceptibility of younger children to illness/infection such as diarrheal disease. There was little difference between boys 38 (4.5\%) and girls $37(4.4 \%)$. Rural areas had a slightly higher prevalence 69 (8.2\%) than urban areas $16(1.9 \%)$. Children of mothers with a higher education were less wasted $2(0.2 \%)$ than children of mothers with no education 48 (5.7\%). Severe wasting was $8(0.9 \%)$ overall and followed the same pattern among the background characteristics that wasting did, higher among younger children, rural areas and lesser educated mothers.

Underweight/weight-for-age/: Among children 6 to 59 months of age, 216 (25.6\%) were underweight. Children 23 to 47 months of age showed the highest percentage of underweight with levels between $55(6.5 \%)$ and $69(8.2 \%)$. Rural areas had a higher percentage of underweight $148(17.5 \%)$ than urban areas $68(8.1 \%)$. Again, levels were higher among lesser educated mothers $127(15 \%)$ than educated mothers $3(0.4 \%)$. Severe underweight was 41 (5\%) overall and followed similar patterns to underweight. Higher levels were seen in children 
Citation: Yalew BM (2014) Prevalence of Malnutrition and Associated Factors among Children Age 6-59 Months at Lalibela Town Administration, North WolloZone, Anrs, Northern Ethiopia. J Nutr Disorders Ther 4: 132. doi:10.4172/2161-0509.1000132

\begin{tabular}{|c|c|c|c|}
\hline Characteristic & $\begin{array}{c}\text { Urban(n=339) } \\
\text { No }(\%)\end{array}$ & $\begin{array}{l}\text { Rural }(n=505) \\
\text { No (\%) }\end{array}$ & $\begin{array}{l}\text { Total }(n=844) \\
\text { No }(\%)\end{array}$ \\
\hline \multicolumn{4}{|c|}{ Depleting colostrum (the first yellow milk) } \\
\hline Give To Child & 278(33) & 411(49) & 689(82) \\
\hline Throw Away & $61(7)$ & 94(11) & 155(18) \\
\hline \multicolumn{4}{|c|}{ Exclusive breast feeding duration } \\
\hline$<6$ months & 20(2) & 10(1) & 30(3) \\
\hline$>6$ months & 319(38) & 495(59) & 814(97) \\
\hline \multicolumn{4}{|c|}{ Pre-lacteal feeding practiced before the age of six months } \\
\hline yes & 70(8) & $88(11)$ & 158(19) \\
\hline No & 269(32) & 417(49) & 686(81) \\
\hline \multicolumn{4}{|c|}{ Type of pre-lacteal feeding $(n=158)$ practiced } \\
\hline $\begin{array}{l}\text { Milk (Other Than Breast } \\
\text { Milk) }\end{array}$ & $60(7)$ & $55(7)$ & $115(14)$ \\
\hline Raw Butter & 10(2) & $32(4)$ & 43(5) \\
\hline \multicolumn{4}{|l|}{ Bottle Feeding Practiced } \\
\hline yes & 62(7) & 175(21) & $237(28)$ \\
\hline No & $277(33)$ & $330(39)$ & $607(72)$ \\
\hline \multicolumn{4}{|l|}{ Meal frequency to the child } \\
\hline Twice a day & $220(26)$ & 304(36) & $524(62)$ \\
\hline Three times a day & 119(14) & $201(24)$ & $320(38)$ \\
\hline \multicolumn{4}{|c|}{ Food items (Minimum dietary diversity) } \\
\hline Two food items & $83(10)$ & 138(16) & $221(26)$ \\
\hline $\begin{array}{l}\text { Three and above food } \\
\text { items }\end{array}$ & $256(30)$ & $367(44)$ & $623(74)$ \\
\hline \multicolumn{4}{|c|}{ Leftover food in the households } \\
\hline Give to children & 104(12) & 192(23) & 296(35) \\
\hline Give to others & $85(10)$ & 110(13) & 195(23) \\
\hline Disposing in the dust bine & 150(18) & 203(24) & 353(42) \\
\hline \multicolumn{4}{|c|}{ Giving meat to child(good feeding tradition) } \\
\hline yes & 294(35) & 429(51) & $723(86)$ \\
\hline No & $45(5)$ & $76(9)$ & $121(14)$ \\
\hline \multicolumn{4}{|l|}{ Giving honey to the child } \\
\hline yes & 104(12) & 122(15) & $226(27)$ \\
\hline No & $235(28)$ & $383(45)$ & $618(73)$ \\
\hline
\end{tabular}

Table 3: Types of feeding practices among children aged 6-59 months by place of resident Lalibela Town, North Wollo Zone, ANRS, Northern Ethiopia, August 2012.

between aged 35 and 47 months, rural areas and lesser educated mothers

\section{Socio-economic, environmental and child health and care} practices associated factors

Associated factors for stunting: Multivaraite logstic regression analysis revealed that age and sex of child, wealth quintile to the household, deworming status and breast feeding child still now were statistically associated with stunting at P-value $<0.05$. Place of residence, family size, pre-lacteal feeding, food groups, first food given at complementary feeding, availability of cow milk in the households, giving meat to the child, meal pattern, landownership, number of harvesting time, hand washing after toilet and distance to fetch drinking water showed some association at p-value 0.2 and less level of significance with stunting.

Children aged 11-24 months were about 2.3 times more likely to be affected by stunting compared to children age 6-11 months $(\mathrm{AOR}=2.30$; (95\%CI: 1.28-4.12). Children age 6-59 months who had not getting deworming service were about 2.2 times more likely to be affected by stunting compared to those who were getting deworming service $(\mathrm{AOR}=2.19$; (95\%CI: 1.41-3.39).

Children age 6-59 months those family had middle wealth quintile were $0.53 \%$ times less likely to be affected by stunting than children whose family had lowest wealth quintile (AOR $=0.53$; (95\%CI: 0.34 0.82). Similarly children from families who had highest wealth quintile were 0.5 times less likely to be affected by stunting compared to children from lowest wealth quintile families (AOR=0.50; (95\%CI: 0.33-0.75).

Children age 6-59 months who had been not gotten breast feed still now were about 0.4 times less likely to be affected by stunting compared to those children who had been getting breast milk still now (AOR=0.40; (95\%CI: $0.20-0.78)$. Sex of the child is also found significantly associated with stunting, Female children were about 0.75 times less likely to be stunted compared to male children $(\mathrm{AOR}=0.75$; (95\%CI: 0.57-1.00).

Associated factors for underweight: Multi-variety logistic regression analysis for underweight shows fourth wealth quintile to the households, highest wealth quintile to the households, age of the child 24-35 months, age of the child 36-47 months, number of children aged 6-59 months in the household, breast feed the child still now and giving honey to the child in the morning were remained to be significantly and independently associated with underweight ( $\mathrm{p}$-value $<0.05$ level of significant).

Children age 6-59 months from families who had a fourth wealth quintile were about 0.5 times less likely to be affected by underweight than children from families who had lowest wealth quintile $(\mathrm{AOR}=0.51$; (95\%CI: 0.28-0.91). Similary children from households who had highest wealth quintile were about 0.46 times less likely to be affected by underweight compared to those children from households who had lowest wealth quintile (AOR=0.46; (95\%CI: 0.24-0.89).

Children age 24-35 months were about 2.3 times more likely to be affected by underweight than children age 6-11 months (AOR=2.29; (95\%CI: 1.14-4.61). Similarly children age 36-47 months were about 2.9 times more likely to be affected by underweight than children age 6-11 months (AOR=2.89; (95\%CI: 1.39-6.01). Children age 6-59 months from households who had more than one child were about 1.6 times more likely to be affected by underweight than children age 6-59 moths from households who had only one child (AOR=1.61; (95\%CI: 1.08 2.41).

Children who had been not breast feed till now were about 0.54 times less likely to be affected by underweight than those children who had been taking breast milk till now (AOR=0.54; (95\%CI: 0.35-0.83). Those children who were not getting honey in the morning were about 1.5 times more likely to be affected by underweight than children who had been getting honey in the morning $(\mathrm{AOR}=1.52$; (95\%CI: 1.03-2.24).

\section{Discussion}

In Ethiopia as well as to the study area and other developing countries, malnutrition among children is a major health problem [14]. The findings of this study revealed that almost half of the study children ages 6-59 months were affected by stunting. The prevalence of stunting, underweight and wasting among children age 6 to 59 months were about $47.3 \%, 25.6 \%$ and $8.9 \%$, respectively. Severe stunting, underweight and wasting (below $-3 \mathrm{SD}$ ) were about $16.2 \%, 5 \%$ and $0.9 \%$, respectively.

\section{Associated factors for stunting}

When we compared the present finding to the cut off point for public health significant, which is $>40 \%$ for stunting, it is too high which needs the attention of all concerned bodies [14].

The EDHS 2011, shows that the prevalence rate of stunting in Amhara, Tigray, Oromiya and SNNPR regions were found as $52 \%$, 
$51.4 \%, 41.4 \%$ and $44.1 \%$, respectively. Stunting in the present study when compared to the above regions was less than Amhara and Tigray regional prevalences. This might be due to difference in method used and sample size variation. In other way the finding of this study was greater than Oromia and SNNPR regional prevalences. This might be due to the farm land in the study area had been more eroded and cultivated for many years.

The prevalence of stunting in East Africa and developing countries were about $48 \%$ and $32 \%$, respectively $[12,13]$. The prevalence of stunting in the study population was approximately the same as that of the population of the East Africa results, but worse than that of the developing countries. This might be due to socio-economic, topographic, developmental and cultural difference.

Sex and age of children were important demographic variables and were the primary basis of demographic classification in surveys. The risk of malnutrition increases with age. The highest risk of stunting was among children age 12-23 months (12\%) and 36-47 months (12\%). Children age 12-23 months were about 2.3 times more likely to be affected by stunting compared to children age 6-11 months (AOR $=2.30$; (95\%CI: $1.28-4.12$ )

This finding was consistent with other studies done in Kartum, Sudan, which shows that the main contributing factors for under-five stunting were found age of the child [25]. Finding from Nairobi also shows, the prevalence of stunting among children age 6-59 months was about $47 \%$, and the prevalence increased with age through 36-47 months (58\%) [22]. In Democratic Republic of Congo which shows, an inverse linear association with age of the child and stunting [20].

Study in Vietnam also indicated that the highest risk of stunting was among children age 12-23 months and Children in the youngest age group, 6-11 months, had a significantly lower risk of being stunted than children in the older age groups [28].

In the current study the high rates of stunting observed after 12 months might be linked to inappropriate food supplementation during the weaning period to stopping breastfeeding earlier than the suggested 24 months. This low risk might be due to the protective effect of breastfeeding, since almost all children, $97 \%$ in the study area were breastfed and most of them continue to be breastfed throughout the first year of their life.

The results of the present study revealed a higher prevalence of stunting in boys $(25.5 \%)$ than girls $(21.8 \%)$. Female children were about 0.75 times less likely to be stunted compared to male children (AOR=0.74; (95\%CI: 0.56-0.98). This were similar to the results of other studies done in Ethiopia, findings from West Gojam shows that male children were about 1.5 times more likely to be stunted than female children [18]. A study done in South Africa has shown that male preschoolers were at higher risk of being stunted than their female counterparts [19]. Study done in Democratic Republic of Congo shows, the prevalence of stunting was higher among boys compared to girls (46.1 versus $41.7 \%$ ) [20].

The cause of this discrepancy in sex is not well established in the literature, but it is believed that boys are more influenced by environmental stress than girls [11].

In the present study children age 6-59 months who had got deworming service were about $86 \%$. Those who had not getting deworming service were about 2.2 times more likely to be affected by stunting compared to those who had gotten deworming service $(\mathrm{AOR}=2.19$; $(95 \% \mathrm{CI}: 1.41-3.39)$.
This finding was in complete agreement with other studies done in India which shows all the three indices of under-nutrition were higher in those with worm infestation [23]. The present finding shows high significant association $(\mathrm{p}<0.001)$ of deworming service with stunting than Indian. This might be due to socio-economic, developmental and topographic variation.

Children from households who had lowest wealth quintile (16\%) were affected by stunting than those children from households of highest wealth quintile (9\%). Children age 6-59 months whose family had middle wealth quintile were about 0.53 times less likely to be affected by stunting than children whose family had lowest wealth quintile (AOR=0.53; (95\%CI: 0.34-0.82). Similarly children from households who had highest wealth quintile were about 0.5 times less likely to be affected by stunting compared to children from lowest wealth quintile family(AOR=0.50; (95\%CI: 0.33-0.75).

This finding was similar to other study done in Ethiopia, EDHS 2011 shows higher proportion of children in the lowest household wealth quintile were stunted (49\%) than children in the highest wealth quintile $(30 \%)$. A study done to southern region of Ethiopia also identified low socioeconomic status of household as risk factors for child under nutrition [23]. This might be due to difference in methods used in this studies and difference in socio-economic, topographic and farming mechanisms.

The child health and care practice in the current study shows that giving leftover food to child (36\%), bottle feeding practiced $(28 \%)$, giving pre-lacteal feeding (19\%) and depilating colostrum (18\%) were high prevalent traditional feeding practices. Breast feeding initiated within one hour of birth for $95 \%$ of the children who are ever breastfed. About $97 \%$ of study subjects were exclusively breast feed until six months of ages.

Children age 6-59 months who had been getting breast feed still now were about 2.5 times more likely to be affected by stunting compared to those children who had been not getting breast milk still now (AOR=0.40; (95\%CI: 0.20-0.78). This might be due to inadequate breast milk if the child did not get appropriate complementary feeding when age increased.

This finding was similar to a study done on 51 selected wored as from Amhara, Tigray, Oromia and SNNPR which shows that the breast feeding practice was estimated to be $98 \%$ but breast feeding was initiated within one hour of birth for $50.4 \%$ of the children who are ever breastfed [8]. About $26 \%$ of the children have been given fluids other than breast milk in the first three days after delivery and it was only $59 \%$ of the children who were fed with colostrums [8].

In the present study initiation of breast feeding practice within one hour was high compared to the above finding. This might be due to wide area coverage and large sample size to the above finding and/or might be due to awareness difference. The study conducted among 25 ethnic groups in central, eastern and southern parts of Ethiopia shows that, not practicing exclusive breastfeeding was experienced in the area [34].

A study conducted in Sudan shows that the main contributing factors for under-five stunting were found as deprivation of colostrums and pre-lacteal feeds [30]. The recent study done from 21 countries determined that, $87.9 \%$ of 6 to 12 months old infants were breastfed [20].

Study from India also show that children who were breastfed for less than six months were 1.6 times more likely to be affected by stunting than those breastfed longer [33]. Apparently, an inverse association is observed between duration of breastfeeding and long-term nutritional 
Citation: Yalew BM (2014) Prevalence of Malnutrition and Associated Factors among Children Age 6-59 Months at Lalibela Town Administration, North WolloZone, Anrs, Northern Ethiopia. J Nutr Disorders Ther 4: 132. doi:10.4172/2161-0509.1000132

status, with longer (> 6 months) of breastfeeding alone associated with increased incidence of stunting [23].

\section{Associated factors for underweight}

The present finding shows $25.6 \%$ of children age 6-59 months were affected by underweight. This finding was lower than the regional (33.4\%) and national figure (29\%) [1]. This might be due to difference in sample size and wide area coverage.

Age of children from 23-35 months was about 2.3 times more likely to be affected by underweight than children age 6-11 months. Similarly children aged 35-47 months were about 2.9 times more likely to be affected by underweight than children age 6-11 months. Eight percent of Children age 35-47 were affected by underweight. This was in complete agreement with other study done in Ethiopia, EDHS 2011, shows the proportion of underweight children was highest in the age groups 24-35 months (34\%) and lowest among those less than six months (10\%). Children 12 to 35 months of age showed the highest percentage of underweight with levels between $6.5 \%$ and $8.2 \%$ [4].

This might be explained by the fact that food for weaning are typically introduced to children in the older age group, thus increasing their exposure to infections and susceptibility to illness. This tendency, coupled with inappropriate or inadequate feeding practices, may contribute to faltering nutritional status among children in these age groups [1]. In developing countries nearly one-third of children are underweight [7]. Study done in Vietnam also revealed that the prevalence of underweight was found to be $31.8 \%$ [11]. The difference might be due to variation in topography and level of development.

The prevalence of underweight for children from lowest and highest wealth quintile families were about $10 \%$ and $4 \%$, respectively. Children age 6-59 months from mothers who had lowest wealth quintile were about two times more likely to be affected by underweight than children from families who had fourth wealth quintile. Similarly children from households who had lowest wealth quintile were about 2.2 times more likely to be affected by underweight compared to those children from households who had highest wealth quintile.

This was consistence with other study done in Ethiopia; EDHS 2011 shows the proportion of underweight children decreases as the wealth quintile of the mother increases. Children born to mothers in the lowest wealth quintile are more than twice as likely to be underweight as children born to mothers in the highest wealth quintile $(36 \%$ compared with 15\%) [1]. A study done to southern region of Ethiopia also identified low socioeconomic status of household as risk factors for child under nutrition [29]. This similarity might be due to the fact that wealthy family can get enough food for his/her children to feed

Children aged 6-59 months from households who had more than one child were about 1.6 times more likely to be affected by underweight than children age 6-59 moths from households who had only one child. This was in contrast to the study conducted in Bangladesh, which shows after adjustment with other factors, number of children in the household appeared to have no significant effect on nutritional status of children [28]. This difference might be due to level of development and economic status.

Children who had been breast feed till now were about 1.9 times more likely to be affected by underweight than those children who had not been taking breast milk till now. This finding was in consistence with other study done in India which shows an inverse association between duration of breastfeeding and long-term nutritional status, with longer (more than 6 months) of breastfeeding without starting complementary food associated with increased incidence of underweight [23].

As a global public health recommendation, infants should be exclusively breastfed for the first six months of life to achieve optimal growth, development and health. Non-exclusive breastfed children in the first 4 months had 3.95 times higher incidence of underweight and thereafter, to meet their evolving nutritional requirements, infants should receive nutritionally adequate and safe complementary foods while breastfeeding continues up to two years or beyond [33]. This indicated that after six months of exclusive breast feeding there must be adequate complementary food to the child. Those children who were not getting honey in the morning were about 1.5 times more likely to be affected by underweight than children who had been getting honey in the morning.

\section{Associated factors for wasting}

The present finding shows $8.9 \%$ of children age 6-59 months were affected by wasting. This finding was lower than the regional $(9.9 \%)$ and national figure (10\%). This might be due to seasonal influence. The present study was conducted in August, rainy season to the area, which help the community to get some vegetables (habasha Gomen) and short duration grains and cereals (cheshoteff, maze, barely etc).

Unlike stunting, younger children were more likely to be wasted than older children. This might be due to the increased susceptibility of younger children to illness/infection such as diarrhoeal disease. There was little difference between boys (4.5\%) and girls (4.4\%). Rural areas had a slightly higher prevalence $(7 \%)$ than urban areas $(1.9 \%)$. Children of mothers with a higher education were less wasted $(0.2 \%)$ than children of mothers with no education (5.6\%). This might be due to difference in food availability between urban and rural areas and due to awareness difference among mothers.

Children from farmer fathers were about 2.5 times more likely to be affected by wasting than those children whose fathers were government employee. This finding was in consistence with other study conducted in Ethiopia, finding by Addis Continental Institute of Public Health shows the primary occupation of father was farmers (91.4\%) [8]. The national nutrition baseline survey also indicated that the main occupation among the rural areas remains farming/agriculture (86\%) [8]. This indicated that children from farmer fathers were more affected by acute malnutrition compared to government employee.

Children who had been breast feed till now were about 4.2 times more likely to be affected by wasting than those children who had not been taking breast milk till now.

\section{Strength and Limitation of the Study}

\section{Strengths}

Considering multiple contributing factors that affect child nutrition may help to use the limited resources more effectively and efficiently.

\section{Limitations}

It was difficult to entertain the seasonal variations. The survey was conducted during a particularly rainy season, which was August, just before the harvest.

There might be potential recall bias among respondents answering questions relating to events happening in the past.

Information on some important confounding variables might not 
Citation: Yalew BM (2014) Prevalence of Malnutrition and Associated Factors among Children Age 6-59 Months at Lalibela Town Administration, North WolloZone, Anrs, Northern Ethiopia. J Nutr Disorders Ther 4: 132. doi:10.4172/2161-0509.1000132

\begin{tabular}{|c|c|c|c|c|}
\hline \multirow[t]{2}{*}{ Predictor } & \multicolumn{2}{|c|}{$\begin{array}{l}\text { Frequency of Stunting } \\
\text { among children age 6-59 } \\
\text { months }\end{array}$} & \multirow[t]{2}{*}{ COR (95\% C.I.) } & \multirow[t]{2}{*}{ AOR (95\% C.I.) } \\
\hline & Stunted & normal & & \\
\hline \multicolumn{5}{|c|}{ Sex of child } \\
\hline Male & 215 & 220 & 1.0 & 1.0 \\
\hline Female & 184 & 225 & $0.84(0.64-1.10)$ & $0.75(0.57-1.00)^{\star}$ \\
\hline \multicolumn{5}{|c|}{ Deworming status } \\
\hline yes & 323 & 403 & 1.0 & 1.0 \\
\hline No & 76 & 42 & $\begin{array}{c}2.26(1.51- \\
3.38)^{* \star *}\end{array}$ & $\begin{array}{c}2.19(1.41- \\
3.39)^{\star * \star}\end{array}$ \\
\hline \multicolumn{5}{|c|}{ Age of child in months ${ }^{* * *}$} \\
\hline $6-11$ & 37 & 39 & 1.0 & 1.0 \\
\hline $12-23$ & 103 & 59 & $\begin{array}{c}1.84(1.06- \\
3.20)^{\star \star *}\end{array}$ & $2.30(1.28-4.12)^{\star \star}$ \\
\hline $24-35$ & 92 & 104 & $0.93(0.55-1.58)$ & $1.34(0.76-2.37)$ \\
\hline $36-47$ & 101 & 137 & $0.78(0.46-1.31)$ & $1.47(0.80-2.69)$ \\
\hline $48-59$ & 66 & 106 & $0.66(0.38-1.13)$ & $1.35(0.70-2.61)$ \\
\hline \multicolumn{5}{|c|}{ The child Still breast feed } \\
\hline Yes & 252 & 204 & 1.0 & 1.0 \\
\hline No & 147 & 241 & $\begin{array}{c}0.49(0.38- \\
0.65)^{\star \star *}\end{array}$ & $0.40(0.20-0.78)^{\star *}$ \\
\hline \multicolumn{5}{|c|}{ Wealth quintile } \\
\hline Lowest & 139 & 120 & 1.0 & 1.0 \\
\hline Second & 33 & 29 & $0.98(0.56-1.71)$ & $0.87(0.48-1.56)$ \\
\hline Middle & 56 & 79 & $0.61(0.40-0.93)^{* \star}$ & $0.53(0.34-0.82)^{\star \star}$ \\
\hline Fourth & 94 & 105 & $0.77(0.53-1.12)$ & $0.72(0.48-1.07)$ \\
\hline Highest & 77 & 112 & $0.59(0.41-0.87)^{\star *}$ & $\begin{array}{c}0.50(0.33- \\
0.75)^{\star \star \star}\end{array}$ \\
\hline
\end{tabular}

Notes: ${ }^{*}=0.05-0.01 \quad * *=0.01-0.001 \quad * * *=<0.001$

NB: Backward stepwise LR method was used to select predictors. The model adequately fits the data at P-value $=0.366$ (Hosmer and Lemeshow goodness of fit test)

Table 4: Logistic regression analysis showing the association of selected socioeconomic and child health and care practice with stunting, Lalibela Town, North Wollo Zone, ANRS, Northen Ethiopia, August 2012.

be collected which could cause problems in interpreting the results. For example, parasitic infestation which is widespread among children (Tables 4-6).

\section{Conclusion}

\section{Conclusions}

- The result of this study described that the prevalence of stunting, underweight and wasting among children age 6-59 months was relatively high. Malnutrition continued to be a substantial burden in children age 6-59 months in Lalibela town.

- Wealth quintile to the households, age and sex of child, deworming status, breast feeding the child till now, number of children aged 6-59 months in the household, giving honey to children and occupation of father were found to be significantly associated with malnutrition.

\section{Recommendations}

\section{For the community}

a) Child age specific attention should be given while feeding. child.

b) Give equal attention for both male and female while feeding the

c) Availability of food alone was not sufficient to address the nutritional security of children, as they need someone to feed them, counsel and guide them, and take them to receive healthcare.

d) Pre-lacteal feeding, giving leftover food to the child, early or late initiation of complementary feeding, were common among the surveyed children, such habits need to be tackled by practicing appropriate feeding.

e) Breast feeding after six months of age needs integration with appropriate complementary feeding.

f) Giving honey with butter in the morning and giving meat to child after age of six should be enguraged by the community.

\section{For the health sector}

a) Regular deworming service to children should be strengthened.

b) Encouraging and strengthening appropriate complementary feeding with breast feeding child after six months of ages.

c) Community management of malnutrition should be strengthened by the health sectors; there was a good start in the community to support malnourished children.

d) Health Extension Workers (HEWs) should strengthen giving participatory nutrition education to create awareness and to develop behavior change communication for better feeding and caring practices among the community.

e) Health care providers are called upon to stress the importance of a nutritious diet in children less than five years of age with mothers. When seeing children for medical care, these health care providers can assess children under five for signs of stunting, wasting, and being underweight.

\section{Other sectors}

a) Wealth quintile for the household directly associated to

\begin{tabular}{|c|c|c|c|c|}
\hline \multirow{2}{*}{ Predictor } & \multicolumn{2}{|c|}{$\begin{array}{c}\text { Underweight among } \\
\text { children aged 6-59 months }\end{array}$} & \multirow{2}{*}{$\operatorname{COR}(95 \% \mathrm{Cl})$} & \multirow{2}{*}{ AOR(95\%Cl) } \\
\hline & Underweight & $\begin{array}{c}\text { Not } \\
\text { underweight }\end{array}$ & & \\
\hline \multicolumn{5}{|c|}{ Wealth quintile } \\
\hline Lowest & 87 & 172 & 1.0 & 1.0 \\
\hline Second & 21 & 41 & $1.01(0.56-1.82)$ & $1.25(0.67-2.35)$ \\
\hline Middle & 39 & 96 & $0.80(0.51-1.26)$ & $0.90(0.54-1.50)$ \\
\hline Fourth & 36 & 163 & $0.44(0.28-0.68)^{\star \star \star}$ & $0.51(0.28-0.91)^{\star}$ \\
\hline Highest & 33 & 156 & $0.42(0.27-0.66)^{* * *}$ & $0.46(0.24-0.89)^{*}$ \\
\hline \multicolumn{5}{|c|}{ Age of child in month } \\
\hline $6-11$ & 15 & 61 & 1.0 & 1.0 \\
\hline $12-23$ & 43 & 119 & $1.47(0.76-2.85)$ & $1.60(0.79-3.24)$ \\
\hline $24-35$ & 55 & 141 & $1.59(0.83-3.02)$ & $2.29(1.14-4.61)^{\star}$ \\
\hline $36-47$ & 69 & 169 & $1.66(0.88-3.12)$ & $2.89(1.39-6.01)^{* *}$ \\
\hline $48-59$ & 34 & 138 & $1.00(0.51-1.97)$ & $1.99(0.89-4.46)$ \\
\hline \multicolumn{5}{|c|}{ Number of children age $6-59$ months } \\
\hline One child & 160 & 521 & 1.0 & 1.0 \\
\hline $\begin{array}{l}\text { More than } \\
\text { one }\end{array}$ & 56 & 107 & $1.70(1.18-2.46)^{\star *}$ & $1.61(1.08-2.41)^{*}$ \\
\hline \multicolumn{5}{|c|}{ Breast feed the child still now } \\
\hline yes & 133 & 323 & 1.0 & 1.0 \\
\hline No & 83 & 305 & $0.66(0.48-0.91)^{*}$ & $0.54(0.35-0.83)^{\star *}$ \\
\hline \multicolumn{5}{|c|}{ Honey to child } \\
\hline yes & 46 & 180 & 1.0 & 1.0 \\
\hline No & 170 & 447 & $1.49(1.03-2.15)^{\star}$ & $1.52(1.03-2.24)^{\star}$ \\
\hline
\end{tabular}

Table 5: Logistic regression analysis showing the association of selected socioeconomic and child health and care practice with underweight, Lalibela Town, North Wollo Zone, ANRS, Northen Ethiopia, August 2012. 
Citation: Yalew BM (2014) Prevalence of Malnutrition and Associated Factors among Children Age 6-59 Months at Lalibela Town Administration, North WolloZone, Anrs, Northern Ethiopia. J Nutr Disorders Ther 4: 132. doi:10.4172/2161-0509.1000132

\begin{tabular}{|c|c|c|c|c|}
\hline \multirow[t]{2}{*}{ Predictor } & \multicolumn{2}{|c|}{$\begin{array}{l}\text { Wasting among children } \\
\text { aged 6-59 months }\end{array}$} & \multirow[t]{2}{*}{ COR(95 \%Cl) } & \multirow[t]{2}{*}{$\operatorname{AOR}(95 \% \mathrm{Cl})$} \\
\hline & Wasted & Not wasted & & \\
\hline \multicolumn{5}{|c|}{ Occupation of father } \\
\hline Farmer & 53 & 348 & 1 & 1 \\
\hline Merchants & 7 & 181 & $0.25(0.11-0.57)^{\star \star \star}$ & $0.20(0.07-0.56)^{\star *}$ \\
\hline $\begin{array}{c}\text { Gov't } \\
\text { Employee }\end{array}$ & 15 & 240 & $0.41(0.23-0.74)^{\star \star}$ & $0.40(0.20-0.87)^{*}$ \\
\hline \multicolumn{5}{|c|}{ Breast feed the child till now } \\
\hline yes & 46 & 410 & 1 & 1 \\
\hline No & 29 & 359 & $0.72(0.44-1.17)$ & $0.24(0.07-0.80)^{*}$ \\
\hline
\end{tabular}

Notes: ${ }^{*}=0.05-0.01 \quad * *=0.01-0.001^{* * *}=\quad<0.001$

NB: Backward stepwise LR method was used to select the above predictors. The model adequately fits the data at P-value $=0.45$ (Hosmer and Lemeshow goodness of fit test)

Table 6: Logistic regression analysis showing the association of selected socioeconomic and child health and care practice with wasting, Lalibela Town, North Wollo Zone, ANRS, Northen Ethiopia, August 2012.

malnutrition of children. Given the mandate for the supply production of adequate and safe food for the community, the agriculture sector needs to strengthening the micro finance enterprise and farming mechanism.

b) Children from illiterate mothers were more likely to be malnourished compared to literate mothers. Being the vital tool for holistic development of the society, education has to be accessed and accelerated so as to bring good health seeking behavior.

c) Further studies might be needed. Such a study might need to be more probing involving other relevant influential community members such as health professionals, husbands, other sector officials and supporting NGOs.

\section{References}

1. Central Statistical Agency. Ethiopia Demographic and health survey. Addis Ababa Ethiopia, 2011.

2. Jansen A, Bailey KO (1972) The Early Detection of childhood Malnutrition in south pacific. Geneva, Switzerland

3. Ramalingaswani V Jonson U, Rhode J (1997) Malnutrition; A south Asia Enigma Malnutrition in south Asia Regional profile. UNICEF Regional office of south Asia publication no 5. Kathrnandu, Nepal 11-22.

4. EHNRI (2009) Baseline survey report for the national nutrition program. Addis Ababa, Ethiopia. 10: 10-12.

5. Mancharia CW, KOG-MAKAU W, Murok NM (2004) Dietary intake, feeding and care practices at children in kathonzweni, Division, Makuenl, district, Kenya. East Africa Medical journal 81: 5-6.

6. United Nation System Standing Committee On Nutrition. (2010) Report On The World Nutrition Situation.

7. Scaling up Nutrition a Framework for Action, the Lancet, and "Maternal and Child Under nutrition," (2008) Special Series 2-10.

8. Addis Continental Institute of Public Health (2009) Community-Based SubComponent of Ethiopian National Nutrition Program Baseline Survey Report.

9. Huffman S, Baker J, Shumann J, Zehner E. (1998) The linkages Project.

10. Deconinck, Bahwere P, Diene SM, Bernardo D, Adou P (October 2011) Summary Report by Hedwig; Community-Based Management of Acute Malnutrition Implementation in West Africa.

11. Hien NN, Kam S (2008) Nutritional status and the characteristics related to malnutrition in children under five years of age in Nghean, Vietnam. J Prev Med Public Health 41: 232-240.

12. FoNSE (2010) Proceedings of the 3rd Annual Conference.

13. Woldemariam G, Timotiows G (2002) Determinants of Nutritional Status of Women and Children in Ethiopia. Ethiopia Health and Nutrition Research Institute, Addis Ababa, Ethiopia.
14. FMOH. (2003) Health sector development programme IV First Year annual performance report, Ethiopia, EFY.

15. Tibilla MA (2007) The nutritional impact of the world food programme-supported supplementary feeding programme on children less than five years in rural tamale, Ghana 17-18.

16. Gobotswang K (2008) Factors associated with nutritional status of the under five children Amita Pradhana. Asian journal of medical sciences.

17. Nguyen NH, Nguyen NH (2009) Nutritional Status and Determinants of Malnutrition in Children Under Three Years of Age in Nghean, Vietnam Pakistan Journal of Nutrition 8: 958-964.

18. Beka T, Wambui K, Zewditu G, Girum T (2009) Magnitude and determinants of stunting in children underfive years of age in food surplus region of Ethiopia: The case of West Gojam Zone. Ethiop. J. Health Development 23: 98-106.

19. Lesiapeto MS (2010) Risk factors of poor anthropometric status in children under five years of age living in rural districts of the Eastern Cape and KwaZuluNatal provinces, South Africa.

20. Kandala NB, Madungu TP, Emina JB, Nzita KP, Cappuccio FP (2011) Malnutrition among children under the age of five in the Democratic Republic of Congo (DRC): does geographic location matter? BMC Public Health 11: 261

21. Nakamori M, Nguyen XN, Nguyen CK, Cao TH, Nguyen AT, et al. (2010) Nutritional status, feeding practice and incidence of infectious diseases among children aged 6 to 18 months in northern mountainous Vietnam. J Med Invest 57: 45-53

22. Olack B, Burke H, Cosmas L, Bamrah S, Dooling K, et al. (2011) Nutritional status of under-five children living in an informal urban settlement in Nairobi, Kenya. J Health Popul Nutr 29: 357-363.

23. Paramita S, Nina P, Benjamin Al (2010) Epidemiological correlates of undernutrition in under- 5 years children in an urban slum of ludhiana, indiaHealth and Population: Perspectives and Issues 33: 1-9.

24. Abuya BA, Ciera J, Kimani-Murage E (2012) Effect of mother's education on child's nutritional status in the slums of Nairobi. BMC Pediatr 12: 80.

25. Ahmed E, Mofida Y, Elkhalifa, Maria H, Elnasik H (2011) Nutritional status of the children under age of five in a desertified area of Sudan; alrawakeeb valley, Khartoum, Sudan. International Journal of Current Research. Vol. 2, Issue, 2 pp.103-108.

26. Babasaheb A. An Investigation into Factors Affecting Child Undernutrition in Madhya Pradesh Sibabrata Das and HariharSahoo. Ravenshaw University Cuttack 753 003, Odisha, India Maharastra, 201: 6-7.

27. Sumonkanti D, Hossain M (2008) Predictors of child chronic malnutrition in Bangladesh.

28. Mostafa KS (2011) Socio-economic determinants of severe and moderate stunting among under-five children of rural Bangladesh. Malays J Nutr 17: 105118

29. Alive \& Thrive. (2010) IYCF Practices, Beliefs, and Influences in SNNPR Region, Ethiopia 2-10.

30. Ajao KO, Ojofeitimi EO, Adebayo AA, Fatusi AO, Afolabi OT (2010) Influence of family size, household food security status, and child care practices on the nutritional status of under-five children in Ile-Ife, Nigeria. Afr J Reprod Health 14(4 Spec no.

31. Assefa D, Wassie E, Getahun M, Berhaneselassie M, Melaku A (2005) Harmfu traditional practices for the Ethiopian health center team,Hawassa, College 33-40.

32. Jayatissa, Moazzem H (Dr), Laksiri N (2012) Assessment of nutritional status and associated factors in Northern Province, Medical research institute in collaboration with UNICEF and WFP Ministry of health, Srilanka.

33. Mohieldin A, Ibrahim M, Alshiek MAH (2008 -2010) The impact of feeding practices on prevalence of under nutrition among 6-59 months aged children in Khartoum 1-2.

34. Sumit M (2012) Assessing Vulnerability to Chronic Undernutrition among Under-Five Children in Egypt. Academic Editor: Abbas Bhuiya 10-12.

35. Alive \& Thrive. (2010) IYCF Practices, Beliefs, and Influences in Tigray Region, Ethiopia.

36. Deconinck H, Bahwere P, Adou P (2010-2011) Review of Community-Based Management of Acute Malnutrition Implementation in Niger 13-28. 
Citation: Yalew BM (2014) Prevalence of Malnutrition and Associated Factors among Children Age 6-59 Months at Lalibela Town Administration, North WolloZone, Anrs, Northern Ethiopia. J Nutr Disorders Ther 4: 132. doi:10.4172/2161-0509.1000132

37. Ethiopia Central Statistical Agency, Addis Ababa, Ethiopia 2007.

38. WHO child growth standards and the identification of severe acute malnutrition in infants and children a joint statement by the world health organization and the United Nations 2009.

39. Indicators for assessing infant and young child feeding practices in Washington DC, USA, WHO 2007.
40. MelkieEdris (2004) Nutrition lecture notes for Health Extension Trainees in Ethiopia, Gondar University, in collaboration with the Ethiopia Public Health Training Initiative, the Carter Center, the Ethiopia Ministry of Health, and the Ethiopia Ministry of Education, November. 